\title{
OBJETOS DE APRENDIZAGEM: UMA PROPOSTA INTERATIVA DE DESENVOLVIMENTO
}

\section{LEARNING OBJECTS: AN INTERACTIVE PROPOSAL OF DEVELOPMENT}

\author{
José Torres ${ }^{1}$, D.Sc. \\ Angelita Mendes², D.Sc. \\ Márcio Souza3, D.Sc.
}

(1) Universidade Federal do Ceará - belo@ufc.br

(2) Universidade Federal de Santa Catarina - angelitamendes56@gmail.com

(3) Universidade Federal de Santa Catarina - marciovieiradesouza@gmail.com

\begin{abstract}
RESUMO
A sistematização do processo de desenvolvimento de objetos de aprendizagem - OAs - melhora a probabilidade de sucesso de sua construção. As metodologias propõem um procedimento, normalmente, baseado no processo de desenvolvimento de software, mas, às vezes, minoram no levantamento das especificações pedagógicas e tecnológicas desses objetos de aprendizagem. Este trabalho, assim, propõe um Processo de Desenvolvimento de OA Interativo - PDOAI - aqui entendido como conjunto de atividades capaz de transformar informações tecnológicas e pedagógicas em Objetos de Aprendizagem, de modo adequar esse processo de desenvolvimento às estratégias da instituição, atendendo às necessidades da sua estrutura de desenvolvimento. Esse processo, então, foi aplicado a uma unidade de uma disciplina de Engenharia, para a qual se mostrou adequada.

Palavras-chave em português: objeto de aprendizagem, metodologia, ambiente virtual de aprendizagem.
\end{abstract}

\begin{abstract}
The systematization of the learning objects' development process increases the probability of success of its construction. The methodologies propose a procedure normally based on the software's development, but sometimes it diminishes the collection of relevance of the pedagogical and technological specifications for those learning objects. The present study thus proposes an Interactive Development Process of Learning Object - PDOAI, in Portuguese - here understood as a set of activities able to transform pedagogical and technological information in Learning Objects, so that it suits that development process to the institution's strategies, by meeting the needs of its development structure. This process was then applied to an Engineering discipline unit, for which it proved to be suitable. Keywords: learning objects, methodology, virtual learning environment.
\end{abstract}




\section{$16^{\circ}$ \\ ERGODESIGN USIHC CINAHPA}

$16^{\circ}$ Ergodesign - Congresso Internacional de Ergonomia e Usabilidade de Interfaces Humano Tecnológica: Produto, Informações Ambientes Construídos e Transporte

$16^{\circ}$ USIHC - Congresso Internacional de Ergonomia e Usabilidade de Interfaces Humano Computador

CINAHPA | 2017 - Congresso Internacional de Ambientes Hipermídia para Aprendizagem.

\section{Introdução}

É evidente a importância dos Objetos de Aprendizagem - OA - atualmente, sobretudo devido às Tecnologias da Informação e Comunicação - TICs, as quais facilitam o seu acesso. Para Braga (2014), OA são unidades digitais, catalogados e disponibilizados em repositórios na Internet para serem utilizados no ensino e na aprendizagem. Esses são constituídos a partir de diversos recursos como vídeo, jogos e textos, por exemplo, nominados individualmente de componentes ou elementos constituintes. $\mathrm{O}$ Instituto de Engenharia Elétrica e Eletrônica, segundo Braga (2014), definiu OA como qualquer entidade, digital ou não, que pode ser usada, reutilizada ou referenciada durante o aprendizado apoiado pela tecnologia. Segundo Abarca (2014), OA, hoje em dia, inclui mais elementos gráficos tornando-o mais atrativos pela redução de conteúdos textuais.

Como um produto ou serviço, um OA é desenvolvido como um projeto. O guia PMBOK, 2008, define projeto como um empreendimento temporário com o objetivo de entregar um produto ou serviço único com começo e fim bem definido. Para o guia PMBOK, 2008, um projeto deve ser constituído de um ciclo de vida e esse deve ser constituído de fases ou etapas e atividades, portanto, um processo de desenvolvimento como referência para o desenvolvimento de um projeto. Assim, o desenvolvimento de um OA deve ser considerado um projeto e deve ter como base um modelo de referência baseado em processo para o seu desenvolvimento.

Assim, para o desenvolvimento de OA é fundamental a utilização de um processo que sirva como referência. O Processo de Desenvolvimento de Produto - PDP, segundo Rozenfeld et al. (2006), é um conjunto de atividades capaz de transformar informações tecnológicas e de mercado em produtos/serviços de acordo com as estratégias da empresa, atendendo às necessidades da produção, acompanhamento e retirada de um produto do mercado. Busca, portanto, a especificação do projeto do produto. Como se verá mais adiante, a proposição objeto deste estudo para o desenvolvimento de OA aproxima-se da definição do PDP.
Mesmo com o modelo de referência, o desenvolvimento de um OA é complexo, principalmente em função do seu reuso. As principais características de um OA são a sua granularidade e a sua agregação. Segundo Braga (2014), de maneira geral, a palavra granularidade origina-se da palavra grão, sendo que quanto maior o número de grãos de um sistema maior a sua granularidade. Trazendo esse conceito para o âmbito do $\mathrm{OA}$, a granularidade é a extensão à qual é composto por componentes ou elementos constituintes menores e reutilizáveis. Assim, um OA é composto de diversos outros OAs menores. Enquanto agregação significa, segundo Braga (2014), a capacidade de seus grãos serem agrupados em conjuntos maiores de conteúdo, um OA pode ter um número de alto de grãos, porém com baixa agregação. Ela justifica essa afirmação por meio de um exemplo de um curso a distância em que cada aula é um grão. Segundo ela, esse curso pode ter uma quantidade alta de grãos, mas, com uma baixa agregação, pois existe uma dependência conceitual entre os grãos, dificultando o reuso do OA. Braga (2014) afirma que um vídeo de 10 minutos tem uma baixa granularidade, mas, pode-se aumentar a granularidade desse OA, editando esse vídeo e o dividindo em 5 vídeos de 2 minutos. Assim, cada vídeo poderia ser apresentado em uma aula diferente e até mesmo em disciplinas diferentes.

Para este trabalho, um OA deve permitir a integração teoria/prática de forma autônoma, e junto com os AVAs possam ser trabalhados para permitir colaborativamente para o ensinoaprendizagem. Como uma característica importante, pode-se citar a flexibilidade no sentido de poder incorporar novos componentes ao OA. Esses componentes podem ser de diversos tipos como um novo problema, uma nova mídia ou um novo texto. Uma outra característica importante é a navegação sobre os seus elementos constituintes. Dessa forma, o software de navegação deve permitir o acesso aos seus elementos de forma que o aluno achar melhor. O software deve permitir acessos paralelos e sequenciais a seus elementos constituintes, ou seja, um elemento só pode ser acessado se um outro já tiver sido acessado e devidamente dominado, por exemplo.

Em função dos aspectos levantados acima, este 
trabalho propõe um modelo de Processo de Desenvolvimento de OA Interativo - PDOAI aqui entendido como conjunto de atividades capaz de transformar informações tecnológicas e pedagógicas em Objetos de Aprendizagem, tendo como objetivo adequar esse processo de desenvolvimento às estratégias da instituição, atendendo às necessidades da sua estrutura de desenvolvimento. Este trabalho está organizado da seguinte forma: na seção 2 é apresentado o levantamento de algumas das metodologias de desenvolvimento de OA. O modelo de processos é apresentado na seção 3 e na seção 4 apresenta-se um estudo de caso para o modelo proposto, enquanto a seção 5 traz as conclusões do estudo.

\section{Objetos de Aprendizagem - Metodologias de Elaboração}

Segundo Braga (2014), a concepção e desenvolvimento de um OA, como também a sua escolha e utilização, deve levar em conta os fatores que determinam uma maior ou menor interatividade e identifica que um deles é a concepção epistemológica e de aprendizagem. Ela exemplifica que se determinado conhecimento deve ser desenvolvido nos alunos, predominantemente, por meio de memorização, certamente, se buscará OA que transmitam informações a serem memorizadas e/ou OAs que apresentarão perguntas para respostas diretas e objetivas, sem exigir muita reflexão. Braga (2014) apresenta como exemplos de casos de memorização: alunos de medicina que necessitam saber o nome de todos os ossos do corpo humano; crianças que precisam aprender a tabuada, e, afirma que um OA pouco interativo, por si só, pode constituir um recurso interessante em uma aula interativa.

Por outro lado, ela afirma que se a concepção for possibilitar o aprendizado do aluno por meio de situações problemas, de forma a colocar em jogo o conhecimento que já possui, ao buscar novas informações e desempenhar papel ativo, deve-se pensar nos OAs que, de alguma maneira, promovam a reflexão do aluno, por meio de desafios e problemas a resolver. Em relação ao processo de desenvolvimento de OAs, são utilizadas diversas ferramentas como mapa conceitual, roteiros, storyboard e mapa de navegação. Em relação ao mapa conceitual, Novak (apud OKADA, 2016) define como uma representação de conceitos e suas relações mediante ligações hierárquicas descritas por palavras que estabelecem relações ou proposições válidas para compreensão de significados dentro de certo domínio de conhecimento.

\subsection{Diretrizes para desenvolvimento de OAs}

Kemczinski (2012) afirma que os OAs devem atender a maioria das características técnicas e pedagógicas, citando interatividade, autonomia, cooperação, cognição e afeto e como caraterísticas técnicas adaptabilidade, agregação, classificação, digital, durabilidade, interoperabilidade e reusabilidade.

\subsection{Levantamentos de processos de desenvolvimento de OAs}

Neste trabalho, foram levantadas várias metodologias de Desenvolvimento de OA ou Design Instrucional - DI. Duas metodologias clássicas de DI como ADDIE - Analysis, Design, Development, Implementation e evaluation $\mathrm{e}$ RIVED foram citadas indiretamente por outras metodologias apresentadas aqui. Em função dos OAs serem considerados objetos digitais, KEMCZINSKI (2012) afirma que um OA é considerado como um produto de software, resultante do processo final da aplicação de uma metodologia, ou seja, DI é definido como processo (conjunto de atividades) para identificar um problema (uma necessidade) de aprendizagem e desenhar, implementar e avaliar uma solução para esse problema. Porém, não é função de uma metodologia proposta, descrever todas as técnicas a serem utilizadas no processo de desenvolvimento de um OA, como vídeos ou jogos. Para o desenvolvimento desses objetos, serão utilizadas metodologias específicas e as técnicas utilizadas estão nos conhecimentos de cada área específica. Para cada fase da metodologia, são gerados artefatos que são avaliados em relação às características pedagógicas e técnicas.

Kemczinski (2012) propôs uma metodologia e chamou de MCOAI - Metodologia de Construção 


\section{$16^{\circ}$ \\ ERGODESIGN USIHC CINAHPA}

$16^{\circ}$ Ergodesign - Congresso Internacional de Ergonomia e Usabilidade de Interfaces Humano Tecnológica: Produto, Informações Ambientes Construídos e Transporte

$16^{\circ}$ USIHC - Congresso Internacional de Ergonomia e Usabilidade de Interfaces Humano Computador

CINAHPA | 2017 - Congresso Internacional de Ambientes Hipermídia para Aprendizagem. de Objetos de Aprendizagem Interativa. Segundo ele, a metodologia é baseada na tradicional área de engenharia de software, porém contando com a interatividade do processo de aprendizagem. Ela consiste em dois pontos principais: (i) a definição das equipes pedagógicas e técnicas; e (ii) a especificação e desenvolvimento do OA. A equipe técnica composta por profissionais com uma base de conhecimento em programação e domínio de ferramentas de desenvolvimento que permitem a interatividade dos OAs, tais como Synfig Studio, Adobe Flash, Java, entre outras. A equipe pedagógica composta por profissionais de domínio da área de conhecimento abordada pelo OA (professores conteudistas). A equipe técnica é responsável pela etapa de implementação, ou seja, em desenvolver o OA com base na especificação gerada pela equipe pedagógica.

A metodologia é baseada em 6 etapas: (i) Análise, (ii) Projeto, (iii) Implementação, (iv) Submissão, (v) Avaliação e (vi) Publicação. Os professores conteudistas da área do OA a ser desenvolvido são responsáveis pelas etapas de Análise e Projeto. Essa equipe é responsável pela construção do mapa conceitual, roteiros e mapa navegacional e, principalmente, pela construção da MDI - Matriz de Design Instrucional. Essa matriz é composta dos atributos como unidade de aprendizagem, objetivos, papéis e definição de atividades responsáveis pelo alcance dos objetivos, duração da aprendizagem e ferramentas e conteúdo de apoio e por último a forma de avaliação dos OAs.

Costa (2014) propõe uma estrutura para especificação dos objetivos da MDI da unidade de aprendizagem relacionada com o processo proposto por Fillatro (apud COSTA, 2014) e pela taxonomia de Bloom. Para cada objetivo especificado, existem quatro atividades introdução, processo, conclusão e avaliação. Além disso, um conjunto de eventos instrucionais são propostos e utilizados para a especificação das atividades. Ele apresenta um exemplo para o preenchimento das atividades na MDI, assim, caso a atividade esteja relacionada à fase de Introdução, o primeiro evento instrucional a ser explanado é ativar a atenção do aluno: ilustrar algoritmo de busca em profundidade no grafo conexo. A figura 1 apresenta a estrutura de especificação das atividades.

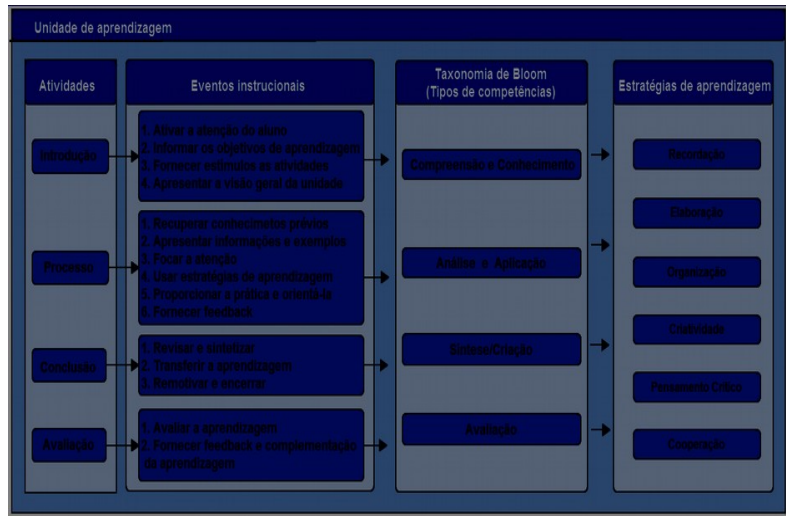

Figura 1. Estrutura de especificação de atividades

Torres et al. (2016) propõem uma metodologia de elaboração de um objeto de aprendizagem com as seguintes etapas: planejamento, elaboração, implementação e avaliação. Como em outras metodologias apresentadas, essas etapas foram compartilhadas pelas equipes técnica e pedagógica. Segundo Torres (2016), as professoras das disciplinas responsabilizaram-se pela análise das necessidades de aprendizagem, por conhecerem os conteúdos e temas que estavam sendo abordados no ensino presencial. Foram propostas as elaborações do mapa conceitual e de roteiro. $\mathrm{O}$ mapa conceitual e os roteiros, com a organização prévia do conteúdo evidenciado pelos mapas conceituais, foram preparados pelo editor de texto (Word), e encaminhados para a equipe de desenvolvimento.

Dessimone (2006) propôs uma metodologia de design de objetos de aprendizagem com bases na engenharia de software educativo e no design de interação. As etapas para efetuar o Design de Objetos de Aprendizagem (DOA) são: Análise do conteúdo; Modelagem de objetos de aprendizagem; Design pedagógico; Design físico; Descrição dos atributos de "metadados". Ela descreveu os resultados ou entregas para cada etapa. Em relação aos resultados das atividades referentes à análise do conteúdo, por exemplo, têm-se: a definição dos elementos constituintes que irão compor o modelo de objetos de aprendizagem pretenso; a identificação e localização dos elementos constituintes catalogados em repositórios disponibilizados na Internet; a análise de objetivos de aprendizagem e análise de atividades de aprendizagem; e a descrição de 


\section{$16^{\circ}$ \\ ERGODESIGN USIHC CINAHPA}

$16^{\circ}$ Ergodesign - Congresso Internacional de Ergonomia e Usabilidade de Interfaces Humano Tecnológica: Produto, Informações Ambientes Construídos e Transporte

$16^{\circ}$ USIHC - Congresso Internacional de Ergonomia e Usabilidade de Interfaces Humano Computador

CINAHPA | 2017 - Congresso Internacional de Ambientes Hipermídia para Aprendizagem. alguns atributos descritores de "metadados" dos elementos constituintes identificados na pesquisa documentária. Enquanto, para a modelagem de objetos de aprendizagem, têm-se os seguintes resultados: o conteúdo pretenso em elementos constituintes; as possíveis relações dos elementos constituintes; os elementos que irão compor o modelo de objetos de aprendizagem. Para realizar a decomposição do conteúdo pretenso, deve-se considerar que os elementos constituintes podem estar descritos em vários formatos, bem como apresentar características de diversos tipos de recursos de apoio didático. Dessimone (2006) recomenda a utilização dos guias pedagógicos e do professor da metodologia RIVED que serve para realização de um checklist para os OAs desenvolvidos.

Braga (2014) propôs uma metodologia chamada INTERA (Inteligência em Tecnologias Educacionais e Recursos Acessíveis) e que foi inspirada nos processos de desenvolvimento de software e no modelo ADDIE para desenvolvimento de conteúdos instrucionais. Ela afirma também que a metodologia proposta deve ser considerada um arcabouço de processos para o desenvolvimento de qualquer tipo de conteúdo digital utilizado para a aprendizagem e que ela é aderente a qualquer tipo de OAs, independentemente de sua granularidade, seu tamanho ou complexidade. Braga (2014) define três fases da metodologia INTERA: inicial, intermediária e de transição e considera os papéis na metodologia INTERA: analista, conteudista, gerente de projetos, demandante, designer de interface, designer instrucional, equipe de desenvolvimento e Equipe de Teste. Ela afirma, também, que para cada etapa deve existir um conjunto de atividades e práticas que variam conforme o tipo de objeto. As etapas da metodologia INTERA são: contextualização, requisitos, arquitetura, desenvolvimento, testes e qualidade, disponibilização, avaliação, gestão de projetos e ambiente e padrões e cada etapa é dividida em 3 elementos: i) entrada; ii) práticas e iii) saída.

Os elementos de entrada são as informações e/ou artefatos necessários para o desenvolvimento das etapas. As práticas são técnicas - já consagradas e utilizadas na área de computação e/ou educação - que podem ser usadas no desenvolvimento de um OA e variam conforme o seu tipo. Essas práticas não fazem parte da metodologia INTERA, no entanto a metodologia recomenda algumas delas. Outros elementos e técnicas também podem ser introduzidos na metodologia de acordo com a necessidade da equipe de trabalho. Os elementos de saída são informações ou artefatos gerados durante ou no final do desenvolvimento da etapa.

Rozenfeld (2008) propõe um modelo de referência baseado no Processo de Desenvolvimento de Produto - PDP. A proposta é dividida nas macrofases, Pré-Desenvolvimento, Desenvolvimento e Pós-Desenvolvimento e estas são divididas, ainda, em fases como Planejamento Estratégico e Planejamento do Projeto (faz parte do PréDesenvolvimento), Projeto Informacional, Projeto Conceitual, Projeto Detalhado, Preparação da Produção, lançamento do Produto (Fazem parte do Desenvolvimento), Acompanhar Produto e Descontinuar (Fazem parte do PósDesenvolvimento). O modelo possui gates que são revisões realizadas ao final de cada fase que Rozenfeld (2006) define como atividade genérica. Ele considera o planejamento uma atividade genérica já que ele é atualizado no início de cada fase. Para cada fase, são realizadas entregas como, por exemplo, uma especificação em forma de documentos.

No projeto informacional, são entregues as especificações-meta, ou seja, as características ou requisitos do produto. A arquitetura do produto é a principal entrega realizada no projeto conceitual. A arquitetura é definida como a composição do produto em função dos seus elementos e a sua integração. Esses elementos são definidos como SSCs, Sistema, Subsistema e Componentes e têm suas especificações iniciais realizadas no projeto conceitual. No projeto detalhado, são desenvolvidos os SSCs de forma integrada.

\section{Proposta de um Processo de Desenvolvimento de OAs}

A proposta deste trabalho foi elaborada a partir de várias metodologias como Braga (2014), Kemczinski et al. (2012), Lucena (2014), Dessimone (2006), Torres (2016) e no Processo de 
Desenvolvimento de Produto - PDP proposto por Rozenfeld (2006). Algumas observações são fundamentais sobre as definições de OAs neste trabalho. Primeiramente, a unidade de aprendizagem da MDI é um tópico quando relacionado com o programa da disciplina. Segundo, tópicos são constituídos de componentes ou elementos constituintes que podem ser definidos como OAs atômicos, ou seja, não permite mais sua decomposição.

Em relação a Rozenfeld (2006), a metodologia utilizou a proposta de seus processos de desenvolvimento de produto - PDP e dos seus aspectos gerenciais. Em relação aos aspectos gerenciais, a metodologia utiliza as atividades genéricas como os gates que são avaliações realizadas no final de cada fase e o planejamento que é atualizado em todo o início do processo de desenvolvimento de uma fase. Além dessas atividades, esta proposta sugere uma atividade de checklist por meio dos guias de orientação pedagógica e de orientação do professor da metodologia RIVED, apresentada por Dessimone (2006). Este checklist apoia a atividade genérica de avaliação. A metodologia proposta, também, utiliza a proposta de Braga (2014) e Rozenfeld (2006) com relação aos processos de entrada (artefatos), processo (práticas ou técnicas) e saída (artefatos) em cada fase. A metodologia, em relação a proposta de Kemczinski (2012), utiliza a MDI. As metodologias apresentadas acima, todas recomendam a utilização das ferramentas como mapa conceitual e storyboard. A MCOAI proposto por Kemczinski (2012) sofreu aprimoramento por Lucena (2014) por meio da proposta de utilização de ferramentas de apoio para o preenchimento da MDI.

Assim, para cada fase, são gerados artefatos que são avaliados pelos gates. Esses artefatos são utilizados, portanto, como entradas para as fases seguintes do método proposto. As fases do Processo de Desenvolvimento de OA Interativo proposto são: Planejamento Estratégico; Planejamento; Projeto Informacional; Projeto Conceitual; Projeto Detalhado; e Disponibilização.

\subsection{Planejamento estratégico}

Esta fase tem como objetivo propor para o seu portfólio os tipos de OAs que serão desenvolvidos na instituição, como software, simulação, jogos, vídeo, textos e animações, por exemplo. Para os OAs mais complexos como software, por exemplo, são necessárias uma estrutura computacional e uma equipe com um conhecimento técnico específico na área de desenvolvimento de software. Dessa forma, as ações sobre os tipos dos OAs, prioridades, início e tempo de seus desenvolvimentos devem ser definidas no planejamento estratégico. As ações sobre desenvolver os OAs ou adquiri-los em outra instituição é uma decisão que deve ser discutida nesta fase, principalmente, para OAs mais complexos. Nesta fase, ainda, devem ser definidos como eles serão gerenciados e quando iniciados.

\subsection{Planejamento}

Nesta fase, são realizadas as etapas de definição do escopo e detalhamento do escopo. O planejamento é considerado uma atividade genérica, ou seja, é atualizado a cada início de cada fase de um projeto. No escopo, são definidas a equipe, o conteúdo da disciplina por meio da sua ementa, a modalidade de ensino, a metodologia adotada, os objetivos, o tempo de início e fim do projeto. No escopo detalhado, é desenvolvida a EAP - Estrutura Analítica de Projeto. Depois da construção da EAP, serão realizados o cronograma e o orçamento do projeto.

Uma observação importante, é que após a fase de projeto conceitual, o planejamento será atualizado e com ele a EAP é detalhada, pois a arquitetura do OA é disponibilizada. A arquitetura de um OA é definida como a estrutura de composição do OA com todos os seus componentes ou elementos constituintes e seus relacionamentos. Uma vez conhecidos os seus elementos constituintes, eles devem ser implementados na fase de projeto detalhado. As etapas para elaboração do planejamento são: definir o escopo do projeto; elaborar o detalhamento do escopo; elaborar o cronograma e elaborar o orçamento do projeto.

\subsection{Projeto informacional}

Para o desenvolvimento do projeto informacional, propõe-se a utilização da MDI (KEMCZINSKI, 2012), com apoio da estrutura de especificação de 
$16^{\circ}$ USIHC - Congresso Internacional de Ergonomia e Usabilidade de Interfaces Humano Computador

CINAHPA | 2017 - Congresso Internacional de Ambientes Hipermídia para Aprendizagem.

atividades propostas por costa (2014). Primeiramente, deve-se dividir os objetivos em quatro fases: introdução, processo, conclusão e avaliação. Em seguida, identifica-se as atividades para as unidades de aprendizagem. Isto é, para cada objetivo e com a seleção de eventos sugeridos pela estrutura de especificação de aprendizagem deve-se buscar as atividades que façam o aluno interagir com o ambiente de aprendizagem. Assim, com o mapa conceitual e a MDI preenchida, podese dar uma visão geral sobre os OAs a serem desenvolvidos. As etapas para elaboração do Projeto Informacional são: elaborar o mapa conceitual das unidades de aprendizagem e preencher as MDIs do projeto. As atividades devem ser transformadas em OAs na fase seguinte projeto conceitual.

\subsection{Projeto conceitual}

Esta etapa tem como objetivo definir a arquitetura do OA. Assim, nesta etapa, serão definidos todos os OAs com seus elementos constituintes. Assim, além dos OAs, são identificados os tipos de OAs e os roteiros de acesso pelos alunos. As informações contidas nas unidades de aprendizagem do projeto informacional servirão de base para a elaboração dos roteiros de acesso a um OA. Primeiramente, ocorre a transformação de cada atividade em elemento constituinte do OA em desenvolvimento. A diferença básica entre a atividade e o elemento constituinte é a forma de definição. A atividade é uma ação, enquanto o elemento constituinte é a descrição de um conteúdo. Propõe-se, também, uma descrição desses elementos constituintes e um roteiro para cada elemento constituinte. Os roteiros definem a sequência dos assuntos a serem apresentados com os tipos dos elementos constituintes a serem utilizados.

No final, o Mapa Navegacional define as rotas de navegação de forma gráfica. Ele influencia a característica pedagógica autonomia e deve possibilitar alternativas de navegação que não causem dúvidas no usuário na utilização do OA. As etapas para elaboração do projeto conceitual são: atualizar o planejamento do projeto; identificar os elementos constituintes dos OAs por meio das atividades; descrever os elementos constituintes dos OAs; identificar o roteiro para cada elemento constituinte; desenvolver o mapa navegacional do OA.

\subsection{Projeto detalhado}

$\mathrm{Na}$ etapa de implementação ocorre a participação dos profissionais técnicos (desenvolvedores), os quais acessarão as informações das etapas anteriores para criarem os OAs. Esta fase tem uma ligação forte com o planejamento estratégico, pois algumas decisões passam pelo seu processo de desenvolvimento, como, por exemplo, desenvolver um OA mais complexo. As escolhas das ferramentas serão discutidas nesta fase, já que no projeto conceitual, ocorreram algumas sugestões das ferramentas. Isto é realizado na atualização do planejamento que é realizado todo início de fase.

\subsection{Disponibilização}

Nesta fase, o OA é disponibilizado no ROA para sua utilização.

\subsection{Atividades genéricas}

As atividades genéricas para esta proposta são: a atualização do planejamento, avaliação ou gates e os checklists com os guias pedagógicos e do professor da metodologia RIVED. A avaliação se dá nas diversas fases da metodologia proposta, porém as avaliações fundamentais são as realizadas antes da fase do projeto detalhado, já que o custo será alto se for identificado um erro nas fases anteriores apenas nesta fase.

Nas diversas fases, devem ser realizadas dois tipos de avaliações, a técnica e a pedagógica. Na avaliação técnica, o avaliador verifica as características técnicas do OA. Nessa etapa, o avaliador técnico pode aceitar ou recusar o objeto de aprendizagem. Se for aceito, o OA é enviado ao avaliador pedagógico, caso contrário o $\mathrm{OA}$ é rejeitado, e o avaliador técnico notifica o gerente do projeto. Na avaliação pedagógica, o avaliador fará a avaliação do OA levando em consideração as características pedagógicas. Nessa etapa, o avaliador pedagógico pode aceitar ou recusar o objeto de aprendizagem. Assim, os professores conteudistas que participaram do projeto informacional e conceitual deverão realizar uma verificação para identificar se as características pedagógicas estão agregadas ao objeto. Caso 


\section{$16^{\circ}$ \\ ERGODESIGN USIHC CINAHPA}

$16^{\circ}$ Ergodesign - Congresso Internacional de Ergonomia e Usabilidade de Interfaces Humano Tecnológica: Produto, Informações Ambientes Construídos e Transporte

$16^{\circ}$ USIHC - Congresso Internacional de Ergonomia e Usabilidade de Interfaces Humano Computador

CINAHPA | 2017 - Congresso Internacional de Ambientes Hipermídia para Aprendizagem. necessite mudanças, a documentação é alterada e o desenvolvedor é informado dos ajustes que precisam fazer. Já no caso de ser validada, o professor conteudista segue para a próxima fase da metodologia.

Após o término da etapa de avaliação, em caso de rejeição, retorna-se à etapa inicial de análise e projeto, para verificar a necessidade de mudança e, após isso, inicia-se a metodologia novamente. Caso o OA seja aceito, entra-se na fase de disponibilização para uso no software de gerenciamento ou ROA.

\section{Estudo de Caso}

Este estudo de caso tem como objetivo avaliar e propor melhoria na metodologia proposta por meio de uma aplicação em disciplina de Projeto Industrial. Para isso, foi selecionada a unidade pesquisa de mercado e, mais especificamente, o tópico de previsão de demanda do programa da disciplina. Não é objetivo, portanto, o desenvolvimento do programa de toda disciplina.

Para validação da proposta, utilizam-se as fases e as ferramentas descritas na metodologia. O mapa conceitual geral da disciplina deve estar disponível para servir de base para o processo de desenvolvimento do OA. Uma outra observação importante é que o tema abordado é multidisciplinar e, por isso, os elementos constituintes do OA deve ser desenvolvido de forma a facilitar sua reutilização.

\subsection{Planejamento}

Neste momento, o projeto foi liberado pelo planejamento estratégico para iniciar o projeto, definindo-se o escopo do projeto. Como pressupõe a metodologia, o mapa conceitual da disciplina com suas unidades e tópicos foi desenvolvido.

A disciplina, portanto, é constituída das seguintes unidades: Conceitos Gerais; Critérios Quantitativos de Análise Econômica de Projetos; Organização das Informações do Projeto. Financiamentos para o Projeto; Estudo de Mercado; Estudo da Localização do Projeto. Determinação da Escala; Tamanho do Projeto; Análise de Risco do Projeto.
A equipe é composta por três professores sendo um responsável mais diretamente pela aplicação da metodologia, já que lecionou a disciplina várias vezes, e os outros dois dando suporte quanto aos aspectos metodológicos e pedagógicos. A modalidade de ensino é híbrida, e a metodologia de ensino é centrada no aluno, usando problemas ou projetos e o conceito de aula invertida. O mapa conceitual é apresentado na figura 2.

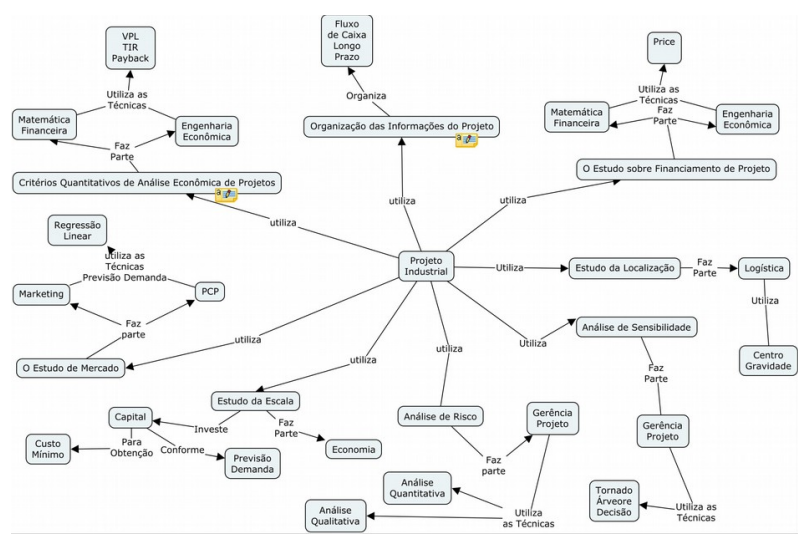

Figura 2. Mapa conceitual da disciplina

Fonte: Autores

$\mathrm{O}$ início do projeto para o tópico Previsão de Demanda, para fins de elaboração do cronograma, foi iniciado em 13.01.2017 e o encerramento no dia 31.01.2017. Os custos orçados são, principalmente, oriundos das horas trabalhadas pelos professores que estarão envolvidos no projeto informacional, conceitual e detalhado. A EAP é constituída, principalmente, das fases da metodologia e das suas entregas para a disciplina Projeto Industrial.

\subsection{Projeto Informacional}

O projeto informacional foi dividido em duas etapas. A primeira etapa é a elaboração do mapa conceitual de cada unidade. A figura 3 mostra o mapa conceitual da unidade Estudo de Mercado que será a unidade estudada neste trabalho. 


\section{ERGODESIGN USIHC CINAHPA}

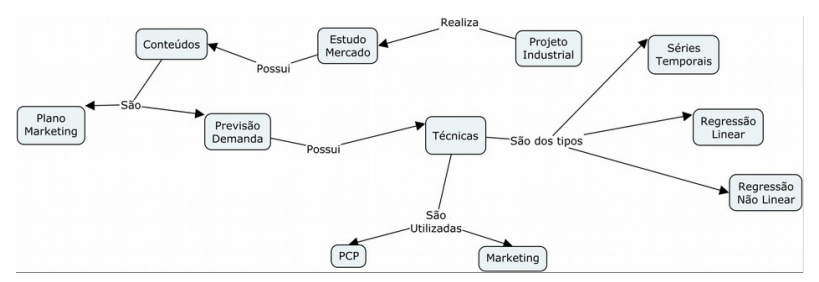

Figura 3. Mapa conceitual da unidade estudada

Fonte: autores

Os elementos do mapa conceitual apoiam a identificação dos tópicos que são candidatos a um OA. Esse OA faz parte de um OA maior chamado de Estudo de Mercado. No mapa, podem ser identificados dois tópicos que devem se tornar OAs, são eles Previsão de Demanda e Plano de Marketing, porém apenas o tópico Previsão de Demandas foi selecionado para este estudo, o qual possui técnicas que são utilizadas em outras disciplinas como Planejamento e Controle da Produção - PCP e Marketing. Os elementos do mapa conceitual apoiam nos processos de especificação dos objetivos e das atividades da MDI.

A segunda etapa está relacionada ao preenchimento da MDI com a especificação dos objetivos e das atividades, e está apresentada nos quadros 1 e 2, a seguir. Para esses quadros, serão mostrados somente uma atividade para cada objetivo dentro de suas fases, embora outras atividades tenham sido identificadas.

Quadro 1. Especificação dos objetivos

\begin{tabular}{|l|l|}
\hline Fase & Objetivos \\
\hline Introdução & $\begin{array}{l}\text { 1Definir conceitos e aplicações de previsão de } \\
\text { demandas }\end{array}$ \\
\hline Processo & 2 Ilustrar as técnicas de previsão de demandas \\
\hline Conclusão & $\begin{array}{l}\text { 3 Formular e aplicar as técnicas de previsão de } \\
\text { demandas em um projeto industrial }\end{array}$ \\
\hline Avaliação & $\begin{array}{l}\text { 4 Avaliar aprendizagem com problemas e questões } \\
\text { sobre previsão de demandas }\end{array}$ \\
\hline
\end{tabular}

Fonte: autores

Quadro 2. Especificação das atividades

\begin{tabular}{|l|l|l|}
\hline Fase & Objetivos & Atividades \\
\hline Introdução & Objetivo 1 & $\begin{array}{l}\text { Apresentar os conceitos e aplicações das } \\
\text { técnicas de previsão de demandas }\end{array}$ \\
\hline Processo & Objetivo 2 & $\begin{array}{l}\text { Explicar os cálculos com as técnicas de } \\
\text { previsão de demandas }\end{array}$ \\
\hline Conclusão & Objetivo 3 & $\begin{array}{l}\text { Elaborar aplicações de previsão de } \\
\text { demandas para projetos industrial }\end{array}$ \\
\hline
\end{tabular}

$16^{\circ}$ Ergodesign - Congresso Internacional de Ergonomia e Usabilidade de Interfaces Humano Tecnológica: Produto, Informações Ambientes Construídos e Transporte

$16^{\circ}$ USIHC - Congresso Internacional de Ergonomia e Usabilidade de Interfaces Humano Computador

CINAHPA | 2017 - Congresso Internacional de Ambientes Hipermídia para Aprendizagem.

\begin{tabular}{|l|l|l|}
\hline Avaliação & Objetivo 4 & $\begin{array}{l}\text { Elaborar questões sobre previsão de } \\
\text { demandas }\end{array}$ \\
\hline
\end{tabular}

Fonte: autores

\subsection{Projeto Conceitual}

Nesta fase, são identificados os elementos constituintes do OA Previsão de Demanda, as interações com os alunos e o roteiro para elaboração do storyboard. O roteiro é identificado a partir do mapa conceitual, da MDI preenchida, e, principalmente dos elementos constituintes, apresentados a seguir no quadro 3,4 e 5 .

Quadro 3. Elementos constituintes

\begin{tabular}{|l|l|}
\hline Atividades & Elementos Constituintes \\
\hline $\begin{array}{l}\text { Apresentar os conceitos } \\
\text { e aplicações das } \\
\text { técnicas de previsão de } \\
\text { demandas }\end{array}$ & $\begin{array}{l}\text { As técnicas de previsão de demanda, conceitos } \\
\text { e suas aplicações }\end{array}$ \\
\hline $\begin{array}{l}\text { Explicar os cálculos } \\
\text { com as técnicas de } \\
\text { previsão de demandas }\end{array}$ & $\begin{array}{l}\text { Fórmulas e cálculos com as técnicas de } \\
\text { previsão de demandas }\end{array}$ \\
\hline $\begin{array}{l}\text { Elaborar aplicações de } \\
\text { previsão de demandas } \\
\text { para projetos industrial }\end{array}$ & $\begin{array}{l}\text { As técnicas de previsão de demandas, } \\
\text { exemplos e soluções para projetos industrial }\end{array}$ \\
\hline $\begin{array}{l}\text { Elaborar questões sobre } \\
\text { previsão de demandas }\end{array}$ & Questões sobre previsão de demandas \\
\hline
\end{tabular}

Fonte: autores

Quadro 4. Descrição dos elementos constituintes

\begin{tabular}{|c|c|c|}
\hline Processos & Elementos constituintes & Descrição \\
\hline Introdução & $\begin{array}{l}\text { As técnicas de previsão } \\
\text { de demanda, conceitos e } \\
\text { suas aplicações }\end{array}$ & $\begin{array}{l}\text { Este elemento tem como } \\
\text { objetivo apresentar as técnicas } \\
\text { de previsão de demandas e suas } \\
\text { aplicações em diversas áreas } \\
\text { como PCP, Marketing e Projeto } \\
\text { Industrial, por exemplo. Assim, } \\
\text { as aplicações podem ser vistas } \\
\text { como de curto, médio e longo } \\
\text { prazo. Podem ser utilizados um } \\
\text { vídeo e um texto para este } \\
\text { elemento. }\end{array}$ \\
\hline Processo & $\begin{array}{l}\text { Fórmulas e cálculos com } \\
\text { as técnicas de previsão de } \\
\text { demandas }\end{array}$ & $\begin{array}{l}\text { Este elemento apresenta } \\
\text { fórmulas e cálculos com } \\
\text { exemplos de aplicações para } \\
\text { previsão de demandas em geral. } \\
\text { Podem ser utilizados vários } \\
\text { vídeos e textos de técnicas de } \\
\text { previsão de demandas para esse } \\
\text { elemento. Existe, pelo menos, } \\
\text { um vídeo e um texto para } \\
\text { aplicações em Projeto } \\
\text { Industrial. }\end{array}$ \\
\hline Conclusão & $\begin{array}{l}\text { As técnicas de previsão } \\
\text { de demandas, exemplos e } \\
\text { soluções para Projeto } \\
\text { Industrial }\end{array}$ & $\begin{array}{l}\text { Este elemento mostra exemplos } \\
\text { e resoluções para aplicações em } \\
\text { Projeto Industrial. Podem ser } \\
\text { utilizados vídeo e texto para } \\
\text { esse elemento. }\end{array}$ \\
\hline Avaliação & $\begin{array}{l}\text { Questões sobre previsão } \\
\text { de demandas }\end{array}$ & $\begin{array}{l}\text { Este elemento tem como } \\
\text { objetivo propor questões sobre }\end{array}$ \\
\hline
\end{tabular}


$16^{\circ}$ USIHC - Congresso Internacional de Ergonomia e Usabilidade de Interfaces Humano Computador

CINAHPA | 2017 - Congresso Internacional de Ambientes Hipermídia para Aprendizagem.

\begin{tabular}{|l|l|}
\hline & $\begin{array}{l}\text { os conteúdos de previsão de } \\
\text { demandas dos diversos } \\
\text { elementos apresentados acima. } \\
\text { Pode ser desenvolvido um } \\
\text { software, como um jogo, para } \\
\text { este elemento. Este elemento é } \\
\text { utilizado em conjunto com o } \\
\text { elemento proposto abaixo. }\end{array}$ \\
\hline
\end{tabular}

Fonte: autores

Quadro 5. Roteiro dos elementos constituintes

\begin{tabular}{|c|c|c|}
\hline $\begin{array}{l}\text { Elementos } \\
\text { constituintes }\end{array}$ & Roteiro & $\begin{array}{l}\text { Tipo de Elementos } \\
\text { Constituintes }\end{array}$ \\
\hline 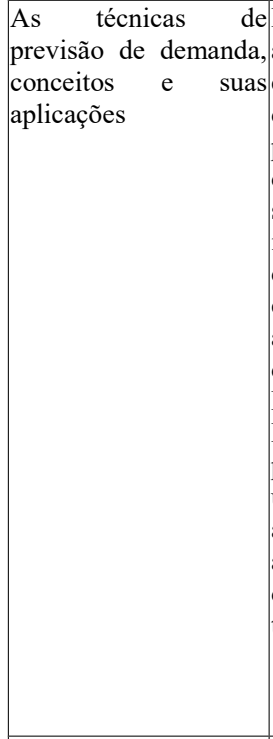 & $\begin{array}{l}\text { Em primeiro lugar é } \\
\text { apresentado o } \\
\text { conceito e objetivo } \\
\text { das técnicas de } \\
\text { previsão de } \\
\text { demandas. Em } \\
\text { seguida, são } \\
\text { identificados os tipos } \\
\text { de técnicas e suas } \\
\text { características e suas } \\
\text { aplicações em } \\
\text { diversas áreas como } \\
\text { PCP, Marketing e } \\
\text { Projeto Industrial, } \\
\text { por exemplo. Por } \\
\text { último, são } \\
\text { apresentadas } \\
\text { aplicações para os } \\
\text { diversos tipos de } \\
\text { técnicas. } \\
\end{array}$ & $\begin{array}{l}\text { Utilizar um texto } \\
\text { único para o elemento } \\
\text { constituinte e um } \\
\text { vídeo com os } \\
\text { conceitos, objetivos e } \\
\text { aplicações sobre as } \\
\text { técnicas de previsão } \\
\text { de demandas. E um } \\
\text { vídeo para cada tipo } \\
\text { de técnica. O } \\
\text { elemento constituinte } \\
\text { é dividido em outros } \\
\text { elementos } \\
\text { constituintes. Assim, } \\
\text { como existem vários } \\
\text { outros elementos } \\
\text { constituintes, utilizar } \\
\text { um software para } \\
\text { gerenciar o roteiro de } \\
\text { acesso a esses } \\
\text { elementos } \\
\text { constituintes pelo } \\
\text { aprendiz. }\end{array}$ \\
\hline $\begin{array}{l}\text { Fórmulas e cálculos } \\
\text { com as técnicas de } \\
\text { previsão de demandas }\end{array}$ & $\begin{array}{l}\text { Inicialmente, são } \\
\text { mostradas as técnicas } \\
\text { e conforme a seleção } \\
\text { pelo aprendiz, são } \\
\text { apresentadas as } \\
\text { fórmulas e cálculos } \\
\text { para técnica de } \\
\text { previsão de } \\
\text { demandas } \\
\text { selecionada. }\end{array}$ & Idem \\
\hline \begin{tabular}{|l|} 
As técnicas de \\
previsão de demandas, \\
exemplos e soluções \\
para projetos industrial \\
\\
\end{tabular} & $\begin{array}{l}\text { Inicialmente, são } \\
\text { mostradas as técnicas } \\
\text { e conforme a seleção } \\
\text { pelo aprendiz, são } \\
\text { apresentados } \\
\text { exemplos e soluções } \\
\text { para a técnica de } \\
\text { previsão de } \\
\text { demandas } \\
\text { selecionada e suas } \\
\text { aplicações em projeto } \\
\text { industrial. }\end{array}$ & Idem \\
\hline \begin{tabular}{|l|} 
Questões sobre \\
previsão de demandas \\
\\
\\
\end{tabular} & $\begin{array}{l}\text { Disponibilizar } \\
\text { questões para } \\
\text { resposta do aprendiz. } \\
\text { Dar um feedback } \\
\text { para o aluno se a } \\
\text { questão foi } \\
\text { respondida de forma } \\
\text { certa ou errada. Em } \\
\text { seguida apresentar }\end{array}$ & Utilizar um software. \\
\hline
\end{tabular}

\section{uma nova questão.}

Fonte: autores

Devido a apresentação ter sido somente para alguns elementos constituintes do OA Previsão de Demandas, este estudo de caso não apresentou o mapa navegacional. Neste trabalho, o mapa foi idealizado com os elementos constituintes de cada fase sendo utilizado de forma paralela. Por exemplo, para fase introdução, três elementos poderiam ser acessados paralelamente, e, em seguida uma avaliação era realizada. Isto foi realizado para as outras fases como processo, conclusão e avaliação.

\subsection{Projeto detalhado}

Nesta fase, também, foram implementados os OAs utilizando o software de autoria eXeLearning. Esta ferramenta foi selecionada em função de sua facilidade de aprendizagem e usabilidade de sua interface.

\section{Conclusão}

O desenvolvimento de OA apropriados e atraentes aos alunos tende a favorecer utilização desses recursos e, portanto, ampliar as possibilidades de incremento das ações pedagógicas com vistas a promover aprendizagem.

Nesse sentido, este estudo analisou metodologias de elaboração de OA e propôs um Processo de Desenvolvimento de OA Interativo - PDOAI como sendo um conjunto de atividades capaz de transformar informações tecnológicas e pedagógicas em OA, conforme a estratégia da instituição, atendendo às necessidades da sua estrutura de desenvolvimento.

Para o desenvolvimento desse processo foram estabelecidas fases, a saber, de Planejamento Estratégico, Planejamento, Projeto Informacional, Projeto Conceitual, Projeto Detalhado e Disponibilização. O estudo de caso realizado para validação da proposta evidenciou a adequação dessa metodologia, na medida em que facilitou o desenvolvimento de $\mathrm{OA}$ adequados às necessidades institucionais. 
$16^{\circ}$ USIHC - Congresso Internacional de Ergonomia e Usabilidade de Interfaces Humano Computador

\section{Referências Bibliográficas}

ABARCA, Reyna Melara (2014) et al. Wikification of Learning Objects Using Metadata as an Alternative Context for Disambiguation. Computación y Sistemas, Vol. 18, No. 4, 2014, pp. $755-765$.

BELLOCH, Consuelo (2017). Diseño Instrucional. Acessado em 04.01.2017.

BRAGA, Juliana (2014) et al. Objetos de Aprendizagem. Volume 1 - Introdução e Fundamentos. Santo André, SP. Editora da UFABC. Coleção INTERA.

(2014) et al. Objetos de Aprendizagem Volume 2 - Metodologia de Desenvolvimento. Santo André, SP. Editora da UFABC. Coleção INTERA.

COSTA, Ismael Antiqueira et al. (2014). Matriz de Design Instrucional da Metodologia para a Construção de Objetos de Aprendizagem Interativos. Nuevas Ideas en Informática Educativa TISE, 2014.

DESSIMONE, Teresa Cristina Gurgel (2006). Design de objetos de aprendizagem com bases na engenharia de software educativo e no design de interação. Dissertação apresentada ao Programa de Pós-Graduação em Ciências da Computação da Universidade Estadual do Ceará. Dezembro de 2006.

KEMCZINSKI, Avanilde et al. (2012). Metodologia para Construção de Objetos de Aprendizagem Interativos. Anais do $23^{\circ}$ Simpósio Brasileiro de Informática na Educação (SBIE 2012), ISSN 2316-6533 Rio de Janeiro, 26-30 de Novembro de 2012.

LUCENA, Sergio Vinícius (2014). Modelagem de requisitos baseada em cenários para o Storyboard da Metodologia para Construção de Objetos de Aprendizagem Interativos. Nuevas Ideas en Informática Educativa TISE 2014.

OKADA, Alexandra (2016). Mapas do Conhecimento com Recursos Educacionais Abertos Aplicados á Coaaprendizagem Baseada em Coinvestiga- ção. Coleção Agrinho. Acessado na Internet em 05.10.2016.

ROZENFELD, Henrique et al. (2006). Gestão do desenvolvimento de produtos: uma referência para melhoria de processos. São Paulo. Editora Saraiva.

TORRES, Patrícia Lupion et al. (2016). O uso de objetos aprendizagem em curso de extensão a distância. Acessado na internet em 22.11.2016 